\title{
Relationship of grooming and rearing to reinforcing stimulation of lateral hypothalamus in rats
}

\author{
DEREK van der KOOY and ANTHONY G. PHILLIPS \\ University of British Columbia, Vancouver, British Columbia, Canada V6T 1W5
}

\begin{abstract}
Grooming and rearing behavior were studied in relation to the reinforcing properties of brain stimulation within a single experimental paradigm. Rats displayed self-stimulation behavior in a shuttlebox by locomoting to and from one side of the box where lateral hypothalamic stimulation was continuously available. Rearing was observed primarily on the stimulation side of the box whereas grooming was observed mainly on the no-stimulation side. These differential associations of grooming and rearing with lateral hypothalamic stimulation were less pronounced under conditions where the same pattern of stimulation was administered noncontingently. The theoretical relationship of species-specific behaviors to reinforcement systems in the rat brain is discussed.
\end{abstract}

Theoretical treatments of reinforcing brain stimulation have often emphasized the close relationship between electrode sites from which various speciesspecific behaviors can be elicited and sites supporting intracranial self-stimulation (Glickman \& Schiff, 1967; Valenstein, Cox, \& Kakolewski, 1970). However, two behaviors that occur frequently in rodents, grooming (Bolles, 1960) and rearing (Schiorring, 1971), have rarely been studied in relation to reinforcing electrical stimulation of the brain. A very fragmentary type of grooming behavior can be elicited from brainstem electrode sites that also support selfstimulation (Ball, Micco, \& Berntson, 1974; Micco, 1974; van der Kooy \& Phillips, Note 1). Another report suggests that grooming most often begins after the termination of brainstem stimulation (Waldbillig, 1975). Comparable studies employing stimulation sites in the lateral hypothalamus have reported either no relationship between reinforcing brain stimulation and grooming (Christopher \& Butter, 1968) or a complex relationship between grooming and the offset of stimulation (Beagley, 1976). Stimulation-elicited rearing has been studied even less in relation to selfstimulation behavior, although Glickman (1973) has demonstrated a relationship between these behaviors in the gerbil.

The fact that elicited behaviors and self-stimulation are often assessed in different situations under different electrical stimulation parameters poses difficulties for interpreting the relation between the behaviors. Self-stimulation is usually assessed by presenting

Supported by Grant A7808 from the National Research Council of Canada. The authors thank Dr. D.M. Wilkie for helpful suggestions during the course of the experiment and Dr. S.J. Shettleworth for comments on the manuscript. short durations $(<1 \mathrm{sec})$ of brain stimulation contingent upon barpressing. In contrast, elicited behaviors are usually studied by repeatedly presenting long durations of stimulation $(15-60 \mathrm{sec})$ noncontingently, each followed by a similar interstimulation interval. Moreover, the reward value of brain stimulation decreases when the stimulation is noncontingent and unsignaled (Cantor \& LoLordo, 1972). In fact, rats will learn to escape brain stimulation delivered noncontingently in exactly the same pattern they had previously generated in a self-stimulation test (Steiner, Beer, \& Shaffer, 1969). Thus, it appears that any direct comparisons between the reinforcing qualities of intracranial stimulation and behaviors elicited by brain stimulation must be made within a single experimental situation.

Fortunately, a shuttlebox apparatus can provide a sensitive assessment of the reinforcing qualities of intracranial stimulation concurrently with the study of elicited behaviors (Phillips, Cox, Kakolewski, \& Valenstein, 1969). In the shuttlebox, stimulation is continually available on one side of the box. Rats generally shuttle back and forth in the box, remaining on each side for periods long enough to permit a fair time sampling of behaviors associated with both the onset and offset of intracranial stimulation. In the present study, the shuttlebox apparatus was employed to investigate the relationships of grooming and rearing to reinforcing stimulation of the lateral hypothalamus.

\section{METHOD}

\section{Subjects and Surgery}

Four male Wistar rats, weighing 300-320 g, were anesthetized with sodium pentobarbital $(50 \mathrm{mg} / \mathrm{kg})$, and bipolar electrodes (Plastic Products Co. MS 303-018-.010") were implanted into the 
lateral hypothalamus. Coordinates for the electrode placements were posterior. $3.1 \mathrm{~mm}$ from bregma, lateral $1.6 \mathrm{~mm}$ from the midline, and ventral $8.6 \mathrm{~mm}$ below the skull. The mouth bar was located $4.2 \mathrm{~mm}$ below the interaural line. Over the course of the experiment, the animals were housed in individual cages and had food and water available ad lib. At the conclusion of the experiment, the subjects were asphixiated with $\mathrm{CO}_{2}$ and their brains were rapidly removed and stored in $10 \%$ Formalin. Brains were frozen and sectioned at $30 \mu$; sections containing electrode tracts were mounted and stained with thionin.

\section{Procedure}

Following recovery from surgery, all animals were tested in one of two identical shuttleboxes $(80 \times 20 \times 35 \mathrm{~cm})$ constructed from sheet aluminum, with a Plexiglas front wall and a grid floor. Two sets of photocells, located in the walls of the runway $15 \mathrm{~cm}$ from each end wall and $4 \mathrm{~cm}$ above the floor, were activated when the subjects crossed from one side of the runway to the other. Breaking a photobeam at one end of the shuttlebox activated an ac constant current stimulator which delivered a variable-intensity $60-\mathrm{Hz}$ sine-wave stimulus through a flexible cable to the chronic electrode assembly. Breaking the beam of the opposite photocell assembly terminated the electrical stimulation. The number of times the stimulator was activated and the duration of the current train were recorded. The occurrence and duration of bouts of grooming and rearing, both during and between each stimulation, were recorded on an Esterline Angus event recorder. Rearing was defined as standing on the hind legs with the forelegs lifted from the floor and either placed against the wall or hanging free. Grooming occurred in three forms: licking the fur, scratching with a hind leg, and washing the face. Duration of each test session in the shuttlebox was always $15 \mathrm{~min}$.

The subjects were initially tested for 4 days in the shuttlebox with no stimulation available in order to habituate them to the experimental apparatus. On the following day, current intensity on the stimulation side of the box was varied to produce approximately twice the operant rate (determined during the last habituation test) of shuttling between each end of the box. The selected current intensities were suboptimal in terms of shuttling rate, but did result in the animals spending appreciable periods of time on both sides of the box. On the next 4 days (the "contingent" condition), stimulation was continuously available on one side of the box. The stimulation side of the box was switched for individual rats each day. Bouts of grooming and rearing were recorded on both the stimulation and no-stimulation sides of the box. During the final 4-day test period (the "noncontingent" condition), a pattern of intracranial stimulation, temporally similar to that responded for during the contingent condition, was administered to each rat by means of an interval timer tape system. The pattern of stimulation was delivered regardless of location of the animal in the box. Bouts of grooming and rearing were recorded during both the stimulation and no-stimulation periods.

\section{RESULTS}

The lateral hypothalamic electrode placements of the four rats are presented in Figure 1. Table 1 presents the average crossing rates $/ 15 \mathrm{~min}$, as well as the mean periods of time spent per crossing on both the stimulation and no-stimulation sides of the box, for individual rats during the contingent condition.

The rearing and grooming data were expressed as percentages of total time that stimulation was on or off during each of the four contingent and noncontingent conditions. These scores were, in turn, averaged over the four trials in each condition, and the means are presented in Figure 2. When stimulation was continuously available on one side of the shuttlebox (i.e., contingent), grooming and rearing were differentially associated with the stimulation and no-stimulation sides of the box. Rearing occurred significantly more $(\mathrm{t}=3.28, \mathrm{p}<.05)$ on the stimulation $(\bar{X}=13 \pm 3 \%)$ than on the no-stimulation side of the box $(\overline{\mathrm{X}}=$ $5 \pm 2 \%$ ). In contrast, significantly more grooming $(\mathrm{t}=7.45, \mathrm{p}<.01)$ was observed on the no-stimulation side than on the stimulation side (i.e., $\bar{X}=33 \pm 11 \%$ vs. $\bar{X} 2 \pm 2 \%$ ). The long durations of grooming seen on the no-stimulation side often consisted of extended sequences of grooming the face, flanks, and back. As the rats ran both towards and away from the stimulation side, it is unlikely that locomotor activity affected the distribution of grooming and rearing in the box.

The data collected during the noncontingent condition differed somewhat from that obtained in the contingent condition. Administering the stimulation regardless of the rat's location in the shuttlebox abolished the difference in duration of rearing behavior previously associated with the stimulation vs. no-stimulation period $(\mathrm{t}=1.80, \mathrm{p}>.05)$. Furthermore, the amount of time spent grooming after the termination of brain stimulation in the noncontingent situation was considerably less than that displayed during the contingent condition, although more grooming was still seen after than during the stimulation $(\mathrm{t}=3.72, \mathrm{p}<.05)$.

\section{DISCUSSION}

The present experiment has demonstrated a differential relationship between grooming, rearing, and reinforcing stimulation of the lateral hypothalamus in rats. Direct comparisons between elicited behaviors and intracranial self-stimulation were facilitated by the use of the shuttlebox apparatus, which avoided the problem of aversive effects of noncontingent brain stimulation (Cantor \& LoLordo, 1972; Steiner et al., 1969). Using this procedure, rearing was primarily associated with the onset of the train of brain stimulation and grooming with the offset. The latter observation appears to confirm a previous report that grooming occurs as an aftereffect of stimulating the lateral hypothalamus (Beagley, 1976).

During the noncontingent stimulation trials, changes in the relative durations of rearing and grooming were observed. The longer durations of rearing seen on the stimulation as compared to nostimulation side of the shuttlebox in the contingent condition were not observed during the noncontingent administration of brain stimulation. The duration of grooming behavior during the no-stimulation periods also decreased under the noncontingent condition, although grooming still occurred more during the no- 


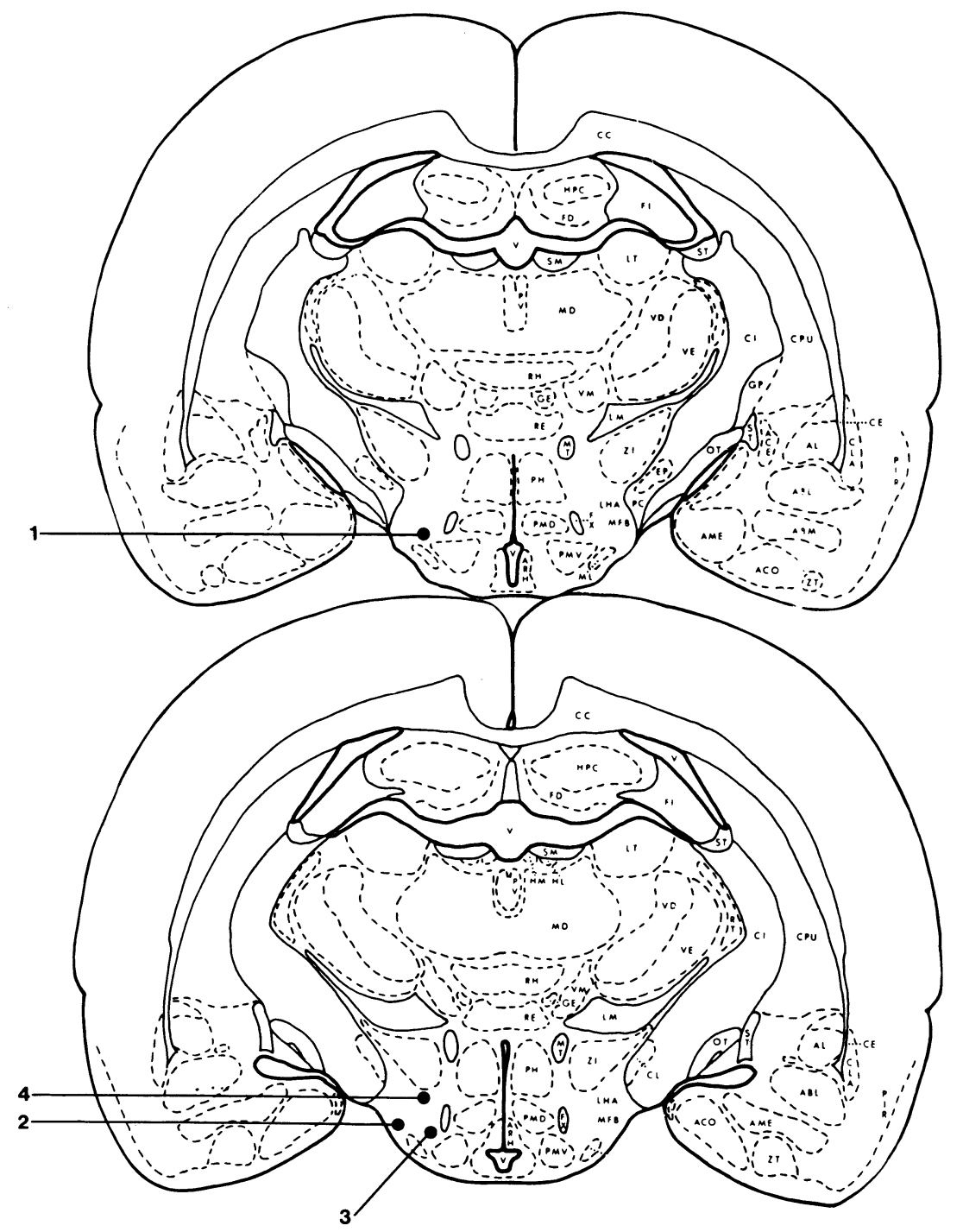

Figure 1. Distribution of electrode placements in the lateral hypothalamus on frontal sections redrawn from Pellegrino and Cushman (1967).

stimulation periods. These results confirm that elicited behaviors do not bear an unvarying relation to the stimulation that elicits them, but are a function of the relation between the brain stimulation, the environment, and the animal's behavior (Phillips et al., 1969). These data also emphasize the problems of making any direct qualitative comparison between the reinforcing properties of intracranial stimulation and elicited behaviors assessed by the noncontingent presentation of brain stimulation.

The predictable relationship between the brain stimulation and a given region of the shuttlebox environment would be disrupted in the noncontingent condition. This must account for the observed changes between contingent and noncontingent conditions in the relationship of a given behavior with

Table 1

Behavior in the Shuttlebox During the "Contingent" Condition

\begin{tabular}{ccccc}
\hline Animal & $\begin{array}{c}\text { Current } \\
\text { Intensity (microA) }\end{array}$ & $\begin{array}{c}\text { Shuttling } \\
\text { Rate/15 min }\end{array}$ & $\begin{array}{c}\text { Average Stimulation } \\
\text { Period Accepted (sec) }\end{array}$ & $\begin{array}{c}\text { Average Interstimulation } \\
\text { Interval (sec) }\end{array}$ \\
\hline 1 & 28 & 30 & 22.9 & 7.0 \\
2 & 30 & 42 & 15.6 & 5.7 \\
3 & 35 & 26 & 15.7 & 18.8 \\
4 & 25 & 15 & 28.0 & 32.0 \\
\hline
\end{tabular}




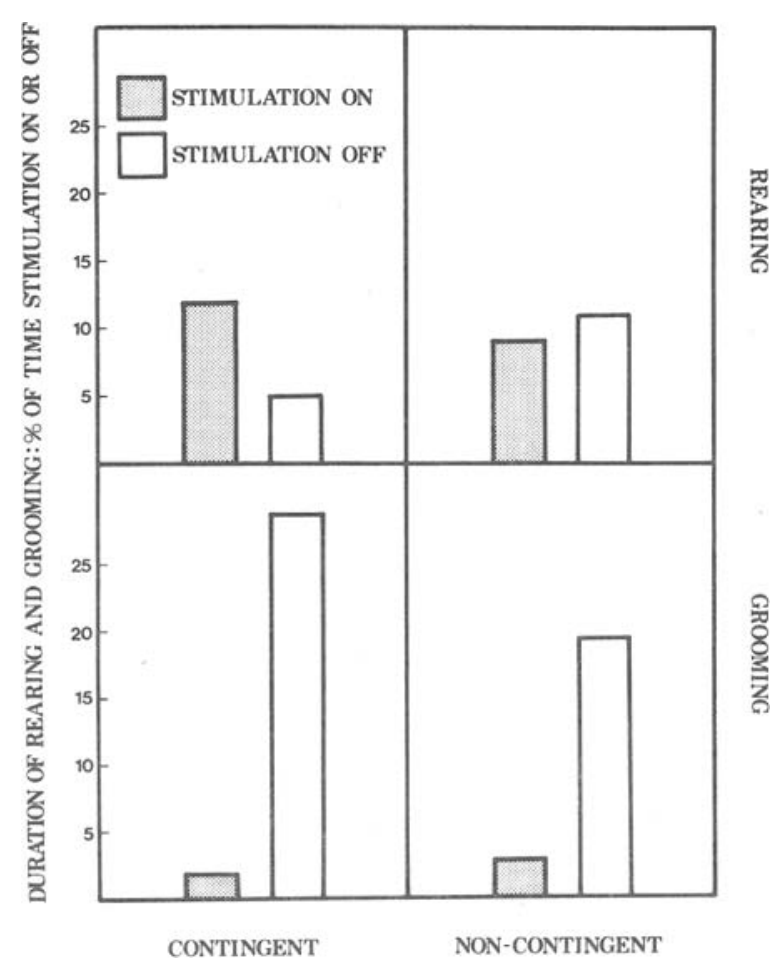

Figure 2. Duration of grooming and rearing during stimulation (closed bars) and no-stimulation (open bars) periods under both the "contingent" and "noncontingent" conditions. Data points represent the mean durations of grooming or rearing expressed as a percentage of either the total stimulation or no-stimulation times.

the onset or offset of brain stimulation. There are at least two (not mutually exclusive) ways in which these changes could take place. First, if the noncontingent application of stimulation was aversive, then conceivably that stimulation might have punished responses that had previously occurred with high frequency under contingent conditions. Second, in the contingent condition the regular relationship between brain stimulation and the sides of the shuttlebox might have produced classically conditioned increases in behaviors that already had special associations with either the offset or onset of the stimulation (Peterson, 1975). Given this second explanation, many of the classically conditioned associations would be disrupted during the noncontingent condition of the present study.

There are a number of interesting parallels between the present attempt to study the relationship between species-specific behavior and reinforcing brain stimulation and previous studies on the efficacy of food reinforcement in conditioning specific action patterns in the hamster (Shettleworth, 1975). In these experiments, it was first observed that action patterns involving locomotion and rearing increased near feeding time, while behaviors such as scent marking and grooming were depressed. When the presenta- tion of food was contingent on the occurrence of one of these action patterns, rearing but not grooming was increased significantly. Shettleworth (1975) suggests that anticipation of a given type of reinforcement facilitates the display of behavior appropriate to the reinforcer. In the example described above, only food-anticipatory action patterns would be expected to increase in duration when reinforced with food. By inference, if a specific pattern of behavior was always associated with reinforcing brain stimulation and that behavior had previously been shown to occur reliably in anticipation of a particular class of "natural" reinforcer, then it might be possible to identify the relationship between brainstimulation reinforcement and natural reinforcers.

Other attempts to specify the response selection properties of different reinforcers have paired a stimulus with the presentation of the reinforcer and observed the behavior displayed towards the conditioned stimulus. In this way, Bindra and Palfai (1967) showed that rats displayed more locomotion and less grooming in response to a conditioned stimulus that predicted the presence of water. Of relevance to the present experiment is the demonstration that rats would sniff at a stimulus that predicted brain stimulation in the lateral hypothalamus (Peterson, 1975).

The results of the present experiment can also be considered in light of those theories of brain stimulation which emphasize the isomorphism between the facilitation of species-specific behaviors and reinforcement (Glickman \& Schiff, 1967). One speciesspecific behavior observed here (i.e., grooming) is related to the offset, rather than onset, of reinforcing lateral hypothalamic stimulation. This appears to go counter to the biological theory of reinforcement proposed by Glickman and Schiff (1967). However, an alternate interpretation of this finding is possible in terms of multiple reinforcement systems in the rat brain. Conceivably, grooming could be associated with a separate reinforcement system that functions, at least partially, in antagonism to the lateral hypothalamic reinforcement system which is associated with rearing. Indeed, it has been reported that grooming can be directly elicited through electrodes implanted in brainstem sites that also support selfstimulation (Ball, Micco \& Berntson, 1974; Micco, 1974; van der Kooy \& Phillips, Note 1). However, this relationship remains to be demonstrated concurrently in the same experimental situation.

\section{REFERENCE NOTE}

1. van der Kooy, D., \& Phillips, A. G. Involvement of the trigeminal system in brainstem self-stimulation and stimulationinduced behavior. Manuscript in preparation.

\section{REFERENCES}

Ball, G. G., Micco, D. J., \& Berntson, G. G. Cerebellar 
stimulation in the rat: Complex stimulation-bound oral behaviors and self-stimulation. Physiology and Behavior, 1974, 13, 123-127.

BEAGLEY, W. K. Grooming in the rat as an after effect of lateral hypothalamic stimulation. Journal of Comparative and Physiological Psychology, 1976, 90, 790-798.

Bindra, D., \& Palfai, T. Nature of positive and negative incentive-motivational effects on general activity. Journal of Comparative and Physiological Psychology, 1967, 63, 288-297.

Bolles, R. C. Grooming behavior in the rat. Journal of Comparative and Physiological Psychology, 1960, 53, 306-310.

Cantor, M. B., \& LoLordo, V. M. Reward value of brainstimulation is inversely related to uncertainty about the onset. Journal of Comparative and Physiological Psychology, 1972, 79, 259-270.

Christopher, S. M., \& Butter, C. M. Consummatory behaviors and locomotor exploration evoked from self-stimulation sites in rats. Journal of Comparative and Physiological Psychology, 1968, 66, 335-339.

Glickman, S. E. Responses and reinforcement. In R. A. Hinde \& J. Stevenson-Hinde (Eds.), Constraints on learning. London: Academic Press, 1973.

Glickman, S. E., \& Schiff, B. B. A biological theory of reinforcement. Psychological Review, 1967, 74, 81-109.

Micco, D. J. Complex behaviors elicited by stimulation of the dorsal pontine tegmentum in rats. Brain Research, 1974, 75, 172-176.

Pellegrino, L. J., \& Cushman, A. J. A stereotaxic atlas of the rat brain. New York: Appleton-Century-Crofts, 1967.
Peterson, G. B. Response selection properties of food and brain-stimulation reinforcers in rats. Physiology and Behavior, 1975, 14, 681-688.

Phillips, A. G., Cox, V. C., Kakolewski, J. W., \& Valenstein, E. S. Elicitation of object carrying by rats: An approach to understanding the behavior produced by brain stimulation. Science, 1969, 166, 903-905.

SchIORRING, E. Amphetamine induced selective stimulation of certain behavior items with concurrent inhibition of others in an open-field test with rats. Behaviour, 1971, 39, 1-17.

ShETTLEWORTH, S. J. Reinforcement and the organization of behavior in golden hamsters: Hunger, environment, and food reinforcement. Journal of Experimental Psychology: Animal Behavior Processes, 1975, 104, 56-87.

Steiner, S. S., Beer, B., \& Shaffer, M: M. Escape from selfproduced rates of brain-stimulation. Science, 1969, 163, 90-91.

Valenstein, E. S., Cox, V. C., \& Kakolewski, J. W. Re-examination of the role of the hypothalamus in motivation. Psychological Review, 1970, 77, 16-31.

WALDBILlig, R. J. Attack, eating, drinking, and gnawing elicited by electrical stimulation of rat mesencephalon and pons. Journal of Comparative and Physiological Psychology, 1975, 89, 206-212.

(Received for publication July 25, 1977; revision accepted December 21, 1977.) 